\title{
Assessing the risks on human health associated with inorganic arsenic intake from groundwater-cultured milkfish in southwestern Taiwan
}

\author{
M.C. Lin ${ }^{\mathrm{a}, *}$, C.M. Liao ${ }^{\mathrm{b}}$

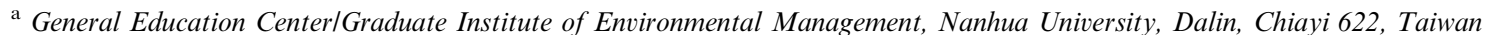 \\ ${ }^{\mathrm{b}}$ Department of Bioenvironmental Systems Engineering, National Taiwan University, Taipei 106, Taiwan
}

Received 15 August 2006; accepted 17 September 2007

\begin{abstract}
The risk of consuming groundwater-cultured milkfish (Chanos chanos) was assessed. Samples of water and milkfish from groundwater-cultured ponds in southwestern Taiwan were analyzed. One third of the 12 sampled ponds had arsenic concentrations in the water higher than $50 \mu \mathrm{g} / \mathrm{L}$, which is the maximum allowed concentration for arsenic in aquacultural water in Taiwan. Of the total amount of arsenic in water, the percentage of inorganic arsenic was $67.5 \pm 8.8 \%$. The inorganic arsenic level in milkfish was $44.1 \pm 10.2 \%$. The bioconcentration factors (BCFs) of milkfish for total arsenic and inorganic arsenic were $11.55 \pm 4.42$ and $6.8 \pm 2.64$, respectively. The target cancer risk (TR) for intake of the milkfish from those ponds was higher than the safe standard $1 \times 10^{-6}$, while in 8 of the ponds the TR values were higher than $1 \times 10^{-4}$. Among the 12 ponds, 7 of those had the target hazard quotient (THQ) for intake of the milkfish higher than the safe standard 1. The actual consumption (IRF) of milkfish from most of those ponds were higher than the calculated acceptable consumption (RBIRF), based on TR $=1 \times 10^{-6}-1 \times 10^{-4}$. Only three sampled ponds (Putai 2, Peimen 2 and Peimen 3 ) did not show differences between the IRF and the RBIRF. Based on the standard TR $=1 \times 10^{-6}$, both the risk-based concentration for inorganic arsenic in milkfish $\left(\mathrm{RBC}_{\mathrm{f}}\right)$ and the risk-based concentration for inorganic arsenic in pond water $\left(\mathrm{RBC}_{\mathrm{w}}\right)$ were lower than the levels of inorganic arsenic in reared milkfish $\left(C_{\mathrm{b}}\right)$ and the concentration of inorganic arsenic in pond water $\left(C_{\mathrm{w}}\right)$, respectively. When the calculation was based on TR $=1 \times 10^{-4}$, only one sampled pond (Putai 3) had a $\mathrm{RBC}_{\mathrm{f}}$ value higher than $C_{\mathrm{b}}$. The inhabitants might be exposed to arsenic pollution with carcinogenic and non-carcinogenic risks.
\end{abstract}

(c) 2007 Elsevier Ltd. All rights reserved.

Keywords: Bioconcentration; Cultured milkfish; Groundwater; Inorganic arsenic; Risk assessment

\section{Introduction}

As a notorious element, arsenic remains a significant human health concern (Tsai et al., 2003). Of the various sources of arsenic in the environment, waterborne arsenic probably poses the greatest threat to human health. Airborne arsenic, particularly through burning arsenic-containing coal and occupational exposure, can also cause problems for human health. Among the natural sources of arsenic contamination, high concentrations are mainly

\footnotetext{
* Corresponding author. Tel./fax: +886 52722295.

E-mail address: mingchaolin@mail.nhu.edu.tw (M.C. Lin).
}

found in groundwater (Smedley and Kinniburgh, 2002). It is toxic for the general population, mainly caused by exposure from drinking water (Liu et al., 2004) and seafood (Donohue and Abernathy, 1999). It has been well recognized that consumption of arsenic, even at low levels, increases the risk of producing or inciting cancer (Buchet et al., 1996; Abernathy et al., 2003; Yu et al., 2003; Chen et al., 2004).

Arsenic has been classified as a carcinogen, based on human epidemiological data (Chiou et al., 1995); arsenic is associated with different kinds of cancers (IPCS, 2001; $\mathrm{Ng}$ et al., 2003). Many reports showed that the population exposed to arsenic-contaminated water in Taiwan, Japan, 
Bangladesh, West Bengal-India, Chile and Argentina have higher cancer risks at skin and various viscera, including lung, bladder, kidney and liver (Mandal and Suzuki, 2002). A significant exposure-response between arsenic concentration and the mortality from cancers has been reported (Chiou et al., 1995; Chen et al., 2004).

Arsenic has been well documented as one of the major risk factors for blackfoot disease (BFD). This disease is considered to be correlated with the consumption of arsenic-contaminated groundwater by local inhabitants living in the four towns, Putai, Yichu, Peimen and Hsuehchia, known as the BFD area, in southwestern Taiwan (Chiou et al., 1995; Lin et al., 2004). An increase in internal organ and skin cancers as well as BFD disease was significantly associated with the use of groundwater (Chen et al., 1999). Today groundwater in this area is no longer used for drinking or cooking, after tap water has been made available in 1970s; however, the groundwater is still used for aquaculture (Lin et al., 2001,2004). Since arsenic can be accumulated in aquatic organisms (Phillips, 1990; Ling et al., 2005), use of high arsenic content groundwater for aquaculture has resulted in an accumulation of arsenic in cultured animals, such as fish. Based on studies carried out so far, it is significant to note that high concentrations of total arsenic were found in cultured fish from the arsenic-contaminated area (Lin et al., 2001,2004; Huang et al., 2003; Liao and Ling, 2003; Liao et al., 2003).

After tilapia (Oreochromis mossambicus), milkfish (Chanos chanos) is the most consumed fish in Taiwan. With high market values, milkfish farming is an important commercial practice. Most of the milkfish aquaculture is located in the coastal region of southwestern Taiwan. Part of that region is situated in and around the four towns in the BFD area mentioned above. A high amount (38,000-49,000 ton/ ha) of freshwater is needed for milkfish culture. Groundwater is used for aquaculture because the water from rivers in this area is too polluted. Several studies have been conducted to demonstrate that to use arsenic-contaminated groundwater for aquaculture may cause an overexposure of arsenic in fish (Lin et al., 2001, 2004; Liao and Ling, 2003; Ling et al., 2005; Ling and Liao, 2007). Ingestion of arsenic-contaminated fish could result in arsenic accumulation in inhabitants and lead to adverse health effects (Falco et al., 2006).

Lin et al. (2005) have estimated the risk of the intake of aquacultural milkfish from the ponds using arsenic-contaminated groundwater. In this study however, the risks were calculated based on the total arsenic level in fish. Phillips (1990) noted that arsenic is more toxic in its inorganic form. Organic arsenic species, such as the methylated arsenic, are less toxic than the inorganic species (Chiou et al., 1995). It has been well known that fish can covert the toxic inorganic arsenicals in their bodies into non-toxic methylated forms. Borum and Abernathy (1994) revealed that the inorganic arsenic in fish is much more toxic than the organic forms. Assessing the risks on human health associated with inorganic arsenic intake from fish is more important than the total arsenic intake. Therefore, target cancer risk (TR) and target hazard quotient (THQ) values should be calculated based on the inorganic arsenic level in fish. In this study, we measured the inorganic arsenic levels and conducted a risk assessment of inorganic arsenic exposure from consuming the arsenic-contaminated milkfish harvested from the groundwater ponds in southwestern region of Taiwan.

\section{Materials and methods}

\subsection{Sampling and preparation}

Scheme of the research procedure is shown in Fig. 1. Samples of water and adult milkfish (body length $35-40 \mathrm{~cm}$, age $1 \mathrm{yr}$ ) from 12 ponds in the four towns, Putai, Yichu, Peimen and Hsuehchia (Fig. 2), in the arseniccontaminated area were analyzed to determine the arsenic level. Only the milkfish in the monoculture ponds reared with groundwater and fed with artificial feed were selected. The groundwater used for culture in these ponds had a salinity of 0 . With three replications for each sample, three $500 \mathrm{ml}$ water samples, three fish and three feedstuffs per pond were collected. The water samples were fixed by adding $5 \mathrm{ml} 1 \mathrm{~N} \mathrm{HNO}_{3}$. After measuring the weight and total length, the milkfish samples were placed on ice immediately and kept at $4{ }^{\circ} \mathrm{C}$ during transfer to the laboratory. The dorsal flesh of the fish was dissected and stored at $-20^{\circ} \mathrm{C}$. The frozen flesh was dehydrated in a dryer $\left(40^{\circ} \mathrm{C}\right)$ for $96 \mathrm{~h}$, and then ground into powder. All water and flesh samples were sent to the Super Micro Mass Research

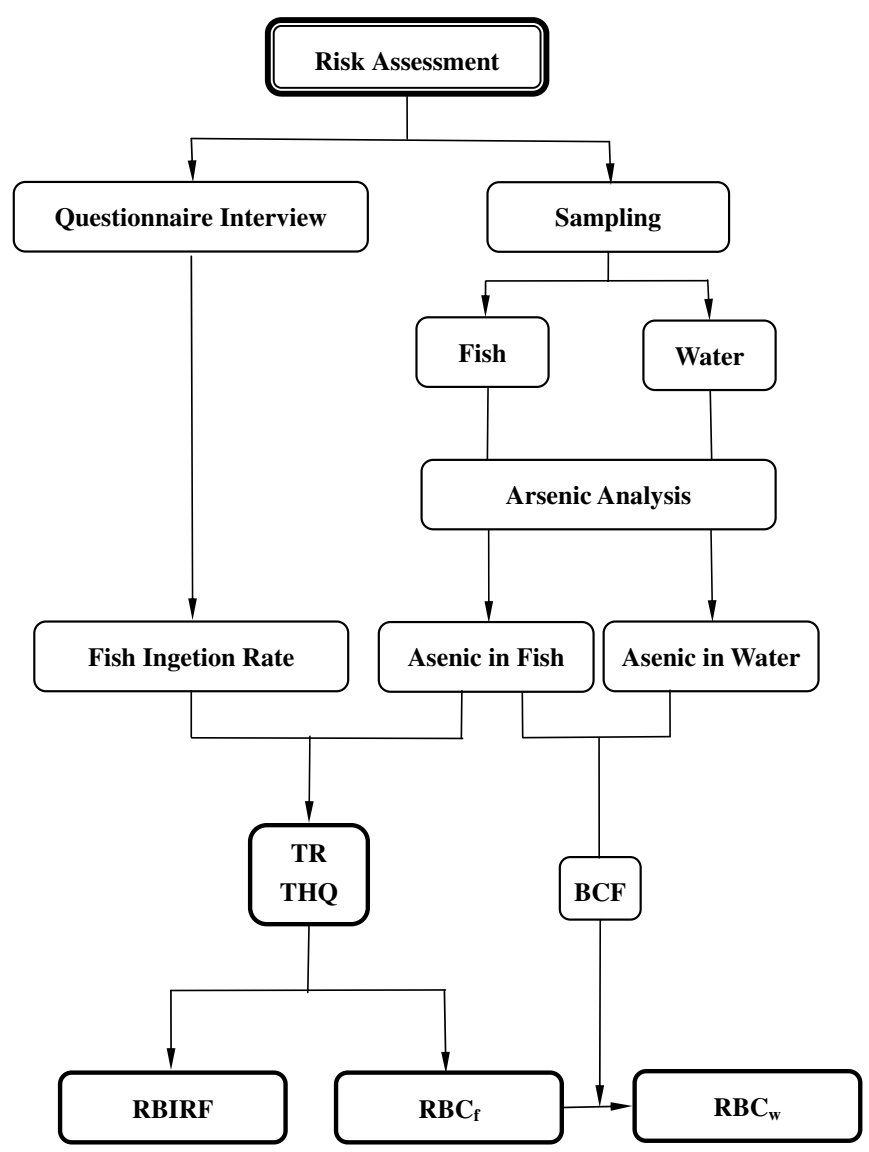

Fig. 1. Scheme of the research procedure (TR: target cancer risk; THQ target hazard quotient; RBIRF: risk-based fish ingestion rate, or acceptable consumption of fish; $\mathrm{RBC}_{\mathrm{f}}$ : risk-based inorganic arsenic concentration in fish; $\mathrm{RBC}_{\mathrm{w}}$ : risk-based inorganic arsenic concentration in water). 


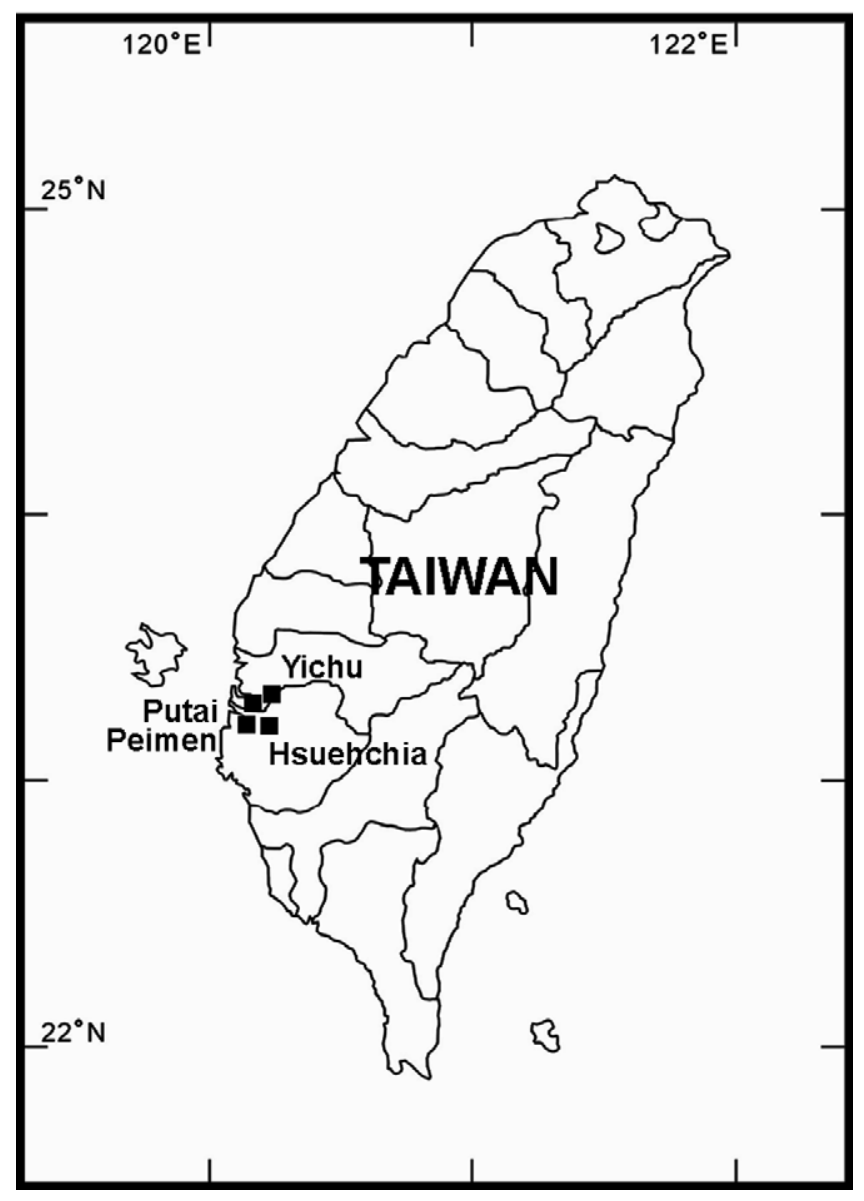

Fig. 2. Map showing locations of sampling sites ( $\mathbf{\square})$ in the southwestern region of Taiwan.

and Technology Center, Cheng Shiu University for analysis of total and inorganic arsenic using Inductively Coupled Plasma Mass Spectrometry (ICP-MS, Agilent 7500a).

The internal standard ( $\mathrm{Sc}, \mathrm{Y}, \mathrm{Tb}$ and $\mathrm{Ho}$ ) and the external standard for arsenic were added to correct for variations in ICP-MS and to verify the sensitivity and stability of the instrument. These standards were used to generate the calibration curves from which the composition of the arsenic samples was inferred. Blank, fortified control and test samples were analyzed to obtain the concentrations of arsenic.

\subsection{Analysis of total arsenic}

Aliquots of dry flesh powder weighing $0.50 \pm 0.01 \mathrm{~g}$ were placed into a $250 \mathrm{ml}$ beaker. Nitric acid $(65 \%, 10 \mathrm{ml})$ was added for an overnight $(12$ $15 \mathrm{~h}$ ) digestion. The beaker with flesh solution, after the digestion, was heated with a water bath (Firstek, B206-T2) at $70-80^{\circ} \mathrm{C}$ for $2-4 \mathrm{~h}$ until the total volume reduced to $1-2 \mathrm{ml}$. The solution was transferred to a volumetric flask $(50 \mathrm{ml})$, and then filled with $0.01 \mathrm{~N}$ of $\mathrm{HNO}_{3}$ to make a $50 \mathrm{ml}$ of final solution. After filtration, this $50 \mathrm{ml}$ solution was transferred to test tubes for arsenic analysis using ICP-MS. Analytical quality control was achieved by digesting and analyzing identical amounts of rehydrated $(90 \%$ $\mathrm{H}_{2} \mathrm{O}$ ) standard reference materials (DORM-2, Dogfish Liver-2-organic matrix, NRC-CNRC, Canada). Recovery rates ranged from $95 \%$ to $97 \%$. The limit of detection (LOD) for arsenic was $0.0052 \mathrm{mg} / \mathrm{kg}$.

\subsection{Analysis of inorganic arsenic}

The methods employed for determination of inorganic arsenic have been described in Munoz et al. (2000) and Hung et al. (2003). The lyophilized flesh powder with a weight of $0.50 \pm 0.01 \mathrm{~g}$ was placed into a $50 \mathrm{ml}$ screw-top centrifuge tube. An amount of $4.1 \mathrm{ml}$ deionized water was added into the tube and then agitated until the sample was completely moistened. After adding $18.4 \mathrm{ml}$ of concentrated $\mathrm{HCl}$, the sample was agitated again for $1 \mathrm{~h}$, and then left to stand for $12-15 \mathrm{~h}$ (overnight). The reducing agent $(1 \mathrm{ml}$ of $1.5 \% \mathrm{w} / \mathrm{v}$ hydrazine sulfate solution and $2 \mathrm{ml}$ of $\mathrm{HBr}$ ) was added and allowed for a 30 -s agitation. An amount of $10 \mathrm{ml}$ $\mathrm{CHCl}_{3}$ was added to the sample for a further agitation of $3 \mathrm{~min}$. The phases were separated by centrifuging at $2000 \mathrm{rpm}$ for $5 \mathrm{~min}$. The chloroform phase was separated by aspiration and poured into another tube. The extraction process was repeated two more times. The chloroform phases were combined and centrifuged again. The remnants of the acid phase were eliminated by aspiration (acid phase remnants in the chloroform phase cause substantial overestimates of inorganic arsenic). Possible remnants of organic material in the chloroform phase were eliminated by passing it through Whatman GD/X syringe filters with a $25 \mathrm{~mm}$ PTFE membrane.

The inorganic arsenic in the chloroform phase was backextracted by agitating for $3 \mathrm{~min}$ with $10 \mathrm{ml}$ of $1 \mathrm{~mol} / \mathrm{L} \mathrm{HCl}$. The phases were separated by centrifuging at $2000 \mathrm{rpm}$, and the aqueous phase was then aspirated and poured into a beaker. This stage was repeated once again and the backextraction phases obtained were combined. When the backextraction phase generated emulsions that could not be broken by centrifuging at over $2000 \mathrm{rpm}$, the emulsion was transferred to the beaker. Ashing aid suspension and $\mathrm{HNO}_{3}$ were added and the result was heated gently in the sand bath for not more than $30 \mathrm{~s}$. The emulsion was then broken and the chloroform phase formed was removed by aspiration.

The determination of inorganic arsenic in the back-extraction phase was performed by means of the following procedure: $2.5 \mathrm{ml}$ of ashing aid suspension and $10 \mathrm{ml}$ of concentrated $\mathrm{HNO}_{3}$ were added to the combined back-extraction phases. The result was evaporated on a sand bath until total dryness, and then dissolved in $3 \mathrm{ml}$ of water. Inorganic arsenic was determined in the water extract using ICP-MS.

\subsection{Questionnaire interview}

A questionnaire interview was conducted to analyze the consumption habits on milkfish of the residents in the four towns mentioned above. We interviewed 141 residents, including the owners of the 12 milkfish ponds from March 2002 to January 2003. A brief questionnaire was filled in with demographic information and data on nutritional habits. The interview questionnaire included detailed questions about milkfish consumption to determine the amount and frequency of consumption. The personal, dietary, and residential information was also obtained.

\subsection{Calculation of bioconcentration factor (BCF)}

The bioconcentration factor $(\mathrm{BCF})$, relating the concentration of arsenic in water to its level in fish (Lin et al., 2004), was used to estimate the propensity of arsenic accumulation in milkfish:

$\mathrm{BCF}=\frac{C_{\mathrm{b}}}{C_{\mathrm{w}}}$

where $C_{\mathrm{b}}(\mathrm{mg} / \mathrm{kg})$ is the arsenic level in fish; $C_{\mathrm{w}}(\mathrm{mg} / \mathrm{L})$ is the arsenic concentration in water.

\subsection{Estimation of potential health risks}

The risk of arsenic accumulation from the ambient water to humans via the milkfish was assessed. All information from the residents, who consume the local cultured milkfish, was classified to evaluate the carcinogenic risks of arsenic exposure. Target cancer risk (TR) and target hazard quotients (THQ) were used to indicate carcinogenic and non-carcinogenic risks. The method to estimate TR and THQ was provided in USEPA Region III Risk-Based Concentration Table (USEPA, 2006). The models for estimating TR and THQ are shown as follows: 
$\mathrm{TR}=\left(C_{\mathrm{b}} \times \mathrm{IRF} \times 10^{-3} \times \mathrm{CPSo} \times \mathrm{EFr} \times \mathrm{EDtot}\right) /(\mathrm{BWa} \times \mathrm{ATc})$

$\mathrm{THQ}=\left(C_{\mathrm{b}} \times \mathrm{IRF} \times 10^{-3} \times \mathrm{EFr} \times \mathrm{EDtot}\right) /(\mathrm{RfD} \times \mathrm{BWa} \times \mathrm{ATn})$

where TR is the target cancer risk; $C_{\mathrm{b}}$ is the arsenic level in fish $(\mathrm{mg} / \mathrm{kg})$; IRF is the fish ingestion rate $(\mathrm{g} / \mathrm{d})$; CPSo is the carcinogenic potency slope, oral $(\mathrm{kg} \mathrm{d} / \mathrm{mg}) ; \mathrm{EFr}$ is the exposure frequency $(350 \mathrm{~d} / \mathrm{yr})$; EDtot is the exposure duration, total ( $30 \mathrm{yr})$; BWa is the body weight, adult $(70 \mathrm{~kg})$; ATc is the averaging time, carcinogens $(25,550 \mathrm{~d})$; THQ is the target hazard quotient; RfD is the reference dose $(\mathrm{mg} / \mathrm{kg} / \mathrm{d})$; ATn is the averaging time, non-carcinogens (EDtot $\times 365 \mathrm{~d} / \mathrm{yr}$ ). The health protection standard of lifetime risk for TR is $1 \times 10^{-6}$, and the standard for THQ is 1 (USEPA, 2006). Since the range for assumable risk is $10^{-4}-10^{-6}$, the maximum amount of milkfish consumption based on acceptable risks of $10^{-4}$ and $10^{-6}$ were both calculated.

The only values of CPSo and RfD for arsenic that we could find were from the USEPA (2006). However, it is not clarified whether those two values refer only to the inorganic arsenic or the total arsenic. The methods employed to determine the risks, associated with inorganic arsenic intake, were described in Han et al. (1998) and Lin et al. (2005). We followed their methods to evaluate potential human health risks (TR and THQ), based on the values of CPSo and RfD for arsenic $\left(1.5 \mathrm{~kg} \bullet \mathrm{d} / \mathrm{mg}\right.$ and $3 \times 10^{-4} \mathrm{mg} /$ $\mathrm{kg} / \mathrm{d}$, respectively), provided by USEPA (USEPA, 2006).

The acceptable consumption of milkfish, or the risk-based fish ingestion rate (RBIRF, g/d), was calculated, based on the arsenic level in fish and the acceptable values for TR, using Eq. (2),

$\mathrm{RBIRF}=\mathrm{TR} \times \mathrm{BWa} \times \mathrm{ATc} /\left(C_{\mathrm{b}} \times 10^{-3} \times \mathrm{CPSo} \times \mathrm{EFr} \times \mathrm{EDtot}\right)$

The actual milkfish consumption and the upper limit for TR were inserted to Eq. (2) to calculate the risk-based concentration of arsenic in milkfish $\left(\mathrm{RBC}_{\mathrm{f}}\right)$. Furthermore, $\mathrm{BCF}$ and $\mathrm{RBC}_{\mathrm{f}}$ values were used to calculate the risk-based concentration of arsenic in water $\left(\mathrm{RBC}_{\mathrm{w}}\right)$ (Lin et al., 2005):

$\mathrm{RBC}_{\mathrm{f}}=\mathrm{TR} \times \mathrm{BWa} \times \mathrm{ATc} /\left(\mathrm{IRF} \times 10^{-3} \times \mathrm{CPSo} \times \mathrm{EFr} \times \mathrm{EDtot}\right)$

$\mathrm{RBC}_{\mathrm{w}}=\mathrm{RBC}_{\mathrm{f}} / \mathrm{BCF}$

where $\mathrm{RBC}_{\mathrm{f}}$ is the risk-based concentration of arsenic in milkfish $(\mathrm{mg} / \mathrm{kg})$; $\mathrm{RBC}_{\mathrm{w}}$ is the risk-based concentration of arsenic in water $(\mathrm{mg} / \mathrm{L})$.

\section{Results}

No arsenic was detected from the feedstuffs. The mean length of sampled milkfish was $37.38 \pm 1.32 \mathrm{~cm}$ and the mean weight was $522.67 \pm 76.25 \mathrm{~g}$. Fig. 3 shows leastsquares linear regressions plotted for the total arsenic level in fish and the total arsenic concentration in water $\left(C_{\mathrm{b}}=\right.$ $\left.0.0092 C_{\mathrm{w}}, R^{2}=0.96\right)$, the inorganic arsenic level in fish and the total arsenic concentration in water $\left(C_{\mathrm{b}}=\right.$ $\left.0.0042 C_{\mathrm{w}}, R^{2}=0.92\right)$, the total arsenic level in fish and the inorganic arsenic concentration in water $\left(C_{\mathrm{b}}=\right.$ $\left.0.0115 C_{\mathrm{w}}, R^{2}=0.95\right)$, and the inorganic arsenic level in fish and the inorganic arsenic concentration in water $\left(C_{\mathrm{b}}=0.0054 C_{\mathrm{w}}, R^{2}=0.96\right) . C_{\mathrm{b}}$ is the arsenic level in fish $(\mathrm{mg} / \mathrm{kg})$ and $C_{\mathrm{w}}$ is the arsenic concentration in water $(\mu \mathrm{g} /$ L). The arsenic level in milkfish showed a significant positively correlating with the arsenic level in pond water $\left(R^{2}>0.9\right)$ (Fig. 3). Among the sampled ponds, Putai 3, Yichu2, Yichu 3 and Hsuehchia 1 had arsenic concentrations higher than the maximum allowed concentration of $50 \mu \mathrm{g} / \mathrm{L}$ for arsenic in aquacultural water in Taiwan, whereas, the other ponds had arsenic concentrations in water higher than $10 \mu \mathrm{g} / \mathrm{L}$ (Fig. 4). The total arsenic levels in milkfish ranged from $0.21 \pm 0.02 \mathrm{mg} / \mathrm{kg}$ to $3.35 \pm$ $0.32 \mathrm{mg} / \mathrm{kg}$, whereas the inorganic arsenic levels ranged
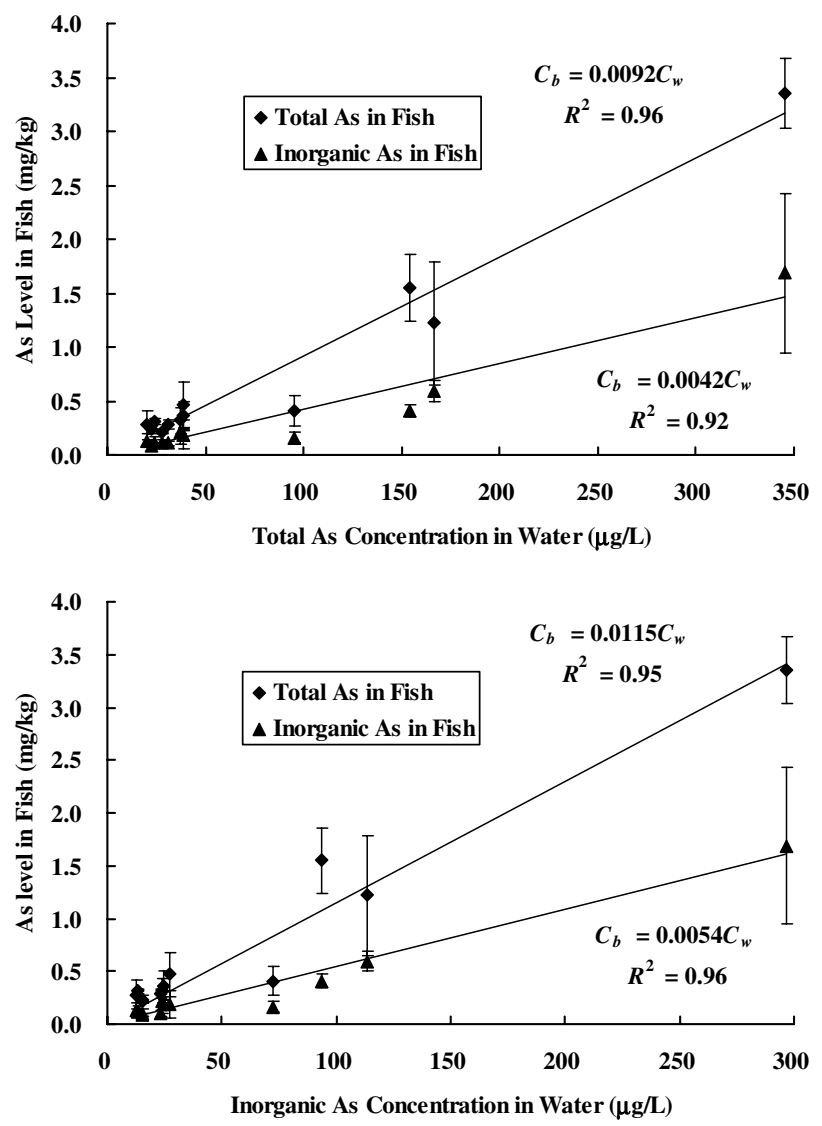

Fig. 3. Plots of the correlation between the arsenic (As) level in milkfish and the arsenic concentration in pond water from the arsenic-contaminated area.

from $0.11 \pm 0.03 \mathrm{mg} / \mathrm{kg}$ to $1.69 \pm 0.74 \mathrm{mg} / \mathrm{kg}$ (Fig. 5). Among the 12 ponds, Hsuehchia 1 had the highest arsenic levels in water and fish.

The percentage of inorganic arsenic in total arsenic in pond water was $67.5 \pm 8.8 \%$, and the percentage of inorganic arsenic in total arsenic in fish was $44.1 \pm 10.2 \%$ (Table 1). The mean BCFs for total and inorganic arsenic accumulated in milkfish were $11.55 \pm 4.42$ and $6.8 \pm 2.64$, respectively. The nutritional habits of the 141 residents from the arsenic-contaminated area showed that the actual consumption on milkfish (IRF) from the 12 ponds, ranging from $103.22 \pm 43.69 \mathrm{~g} / \mathrm{d}$ to $374.07 \pm 134.22 \mathrm{~g} / \mathrm{d}$, were all higher than the acceptable consumption (RBIRF) based on $\mathrm{TR}=1 \times 10^{-6}$, ranging from $0.08 \pm 0.03 \mathrm{~g} / \mathrm{d}$ to $1.36 \pm$ $0.21 \mathrm{~g} / \mathrm{d}$ (Fig. 6). While the BRIRF was calculated based on TR $=1 \times 10^{-4}$, the IRFs from most of those ponds were higher than their RBIRFs. Only Putai 2, Peimen 2 and Peimen 3 showed no significant difference between the IRF and the RBIRF (Fig. 6).

The values of TR and THQ were calculated based on the median values of consumption rates. The values of TR for consuming milkfish from varied ponds, ranging from $4.77 \times 10^{-5} \pm 6.92 \times 10^{-6}$ to $7.26 \times 10^{-4} \pm 3.19 \times$ $10^{-4}$, were all higher than the acceptable risk $1 \times 10^{-6}$ (Table 2). It shows that the inhabitants from the arsenic- 


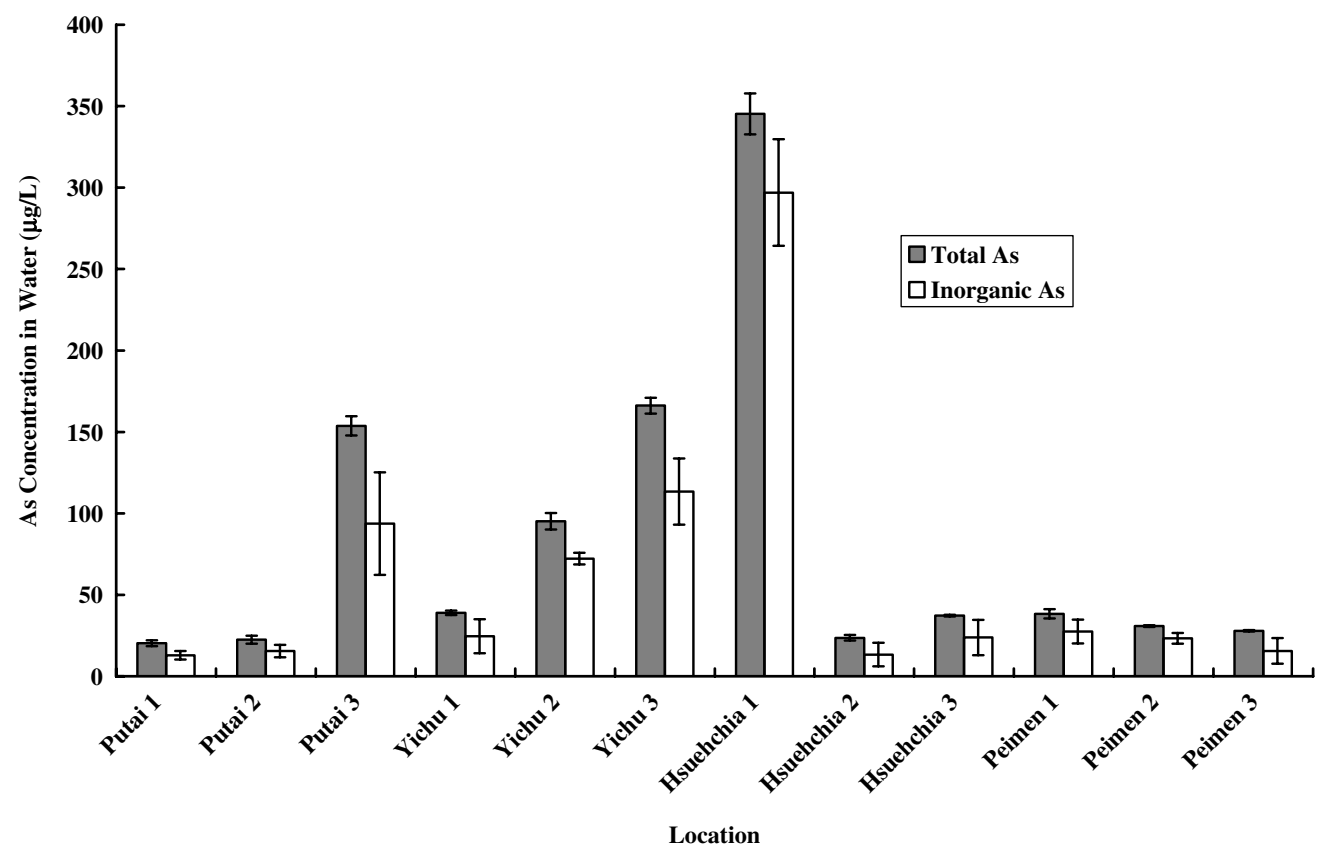

Fig. 4. Total and inorganic arsenic (As) concentrations in pond water from the arsenic-contaminated area.

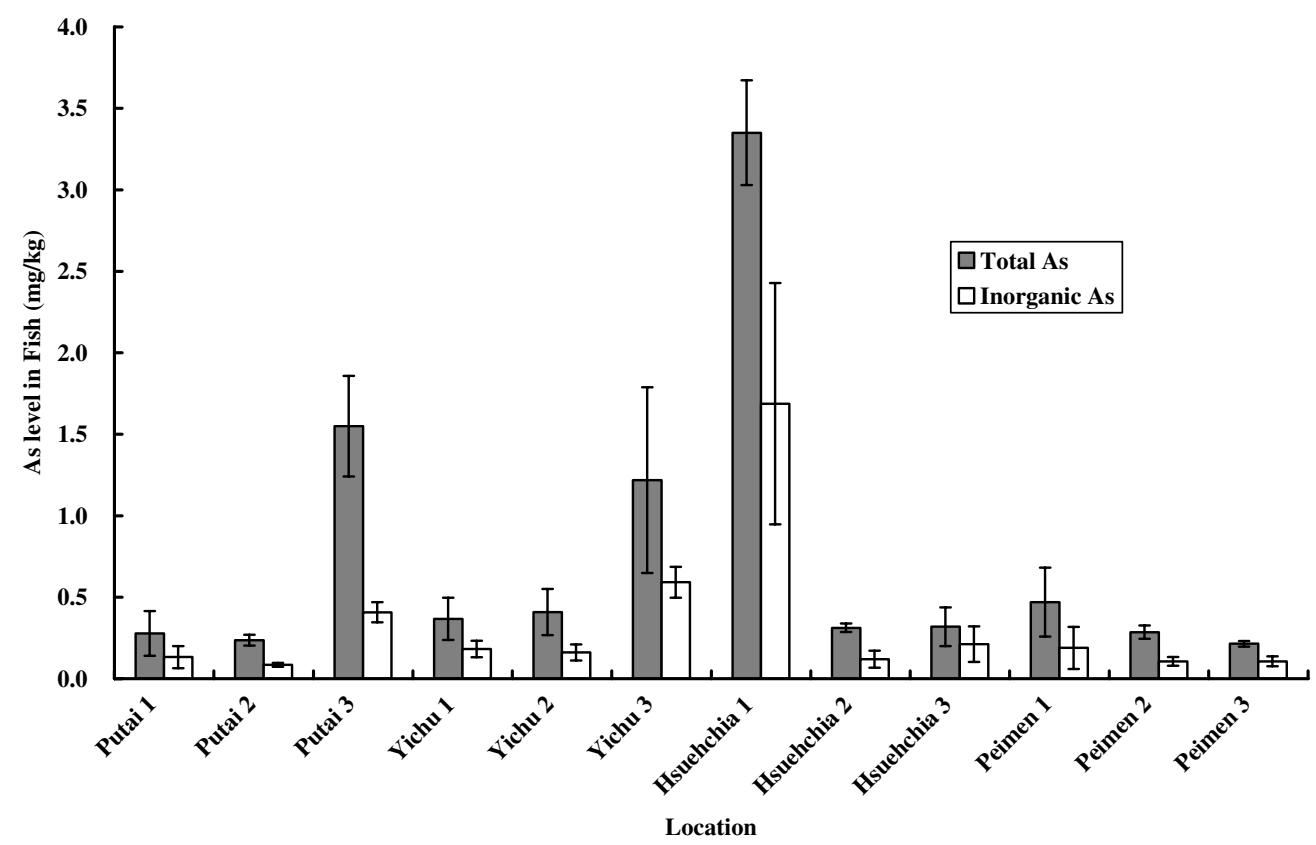

Fig. 5. Total and inorganic arsenic (As) levels in milkfish from the arsenic-contaminated area.

contaminated area were exposed to arsenic pollution with a carcinogenic risk based on the standard $1 \times 10^{-6}$, while in 8 of the ponds the risk was higher than $1 \times 10^{-4}$. The values of THQ for intake of the milkfish ranged from $0.25 \pm 0.04$ to $3.76 \pm 1.65$ (Table 2). Among the 12 ponds, 7 of them had THQ values higher than the safe value 1 , which demonstrates a non-carcinogenic risk for humans. The residents consuming the milkfish from the pond Hsuehchia 1 had the highest carcinogenic and non-carcinogenic risks.
The risk-based concentrations $\left(\mathrm{RBC}_{\mathrm{f}}\right)$ for inorganic arsenic level in milkfish (ranging from $8.70 \times 10^{-4} \pm$ $4.59 \times 10^{-4} \mathrm{mg} / \mathrm{kg}$ to $1.14 \times 10^{-2} \pm 7.09 \times 10^{-4} \mathrm{mg} / \mathrm{kg}$ for $\mathrm{TR}=1 \times 10^{-6}$ and ranging from $8.70 \times 10^{-2} \pm 4.59 \times$ $10^{-2} \mathrm{mg} / \mathrm{kg}$ to $1.14 \pm 7.09 \times 10^{-2} \mathrm{mg} / \mathrm{kg}$ for $\mathrm{TR}=1 \times$ $10^{-4}$ ) were mostly lower than the amounts we obtained from the fish samples (ranging from $0.08 \pm 0.01 \mathrm{mg} / \mathrm{kg}$ to $1.69 \pm 0.74 \mathrm{mg} / \mathrm{kg}$ ). Only in Putai 3 the $\mathrm{RBC}_{\mathrm{f}}$ was higher than the value we obtained from the field data (Tables 1 
Table 1

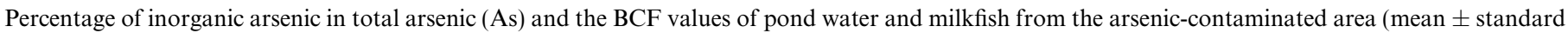
error)

\begin{tabular}{|c|c|c|c|c|}
\hline Location & $\begin{array}{l}\text { Percentage of inorganic As in } \\
\text { total As in water }(\%)\end{array}$ & $\begin{array}{l}\text { Percentage of inorganic As in } \\
\text { total As in fish }(\%)\end{array}$ & $\mathrm{BCF}$ of total As & $\mathrm{BCF}$ of inorganic As \\
\hline Putai 1 & 63.4 & 47.7 & $14.09 \pm 7.71$ & $11.05 \pm 7.44$ \\
\hline Putai 2 & 68.8 & 36.0 & $10.51 \pm 1.04$ & $5.82 \pm 2.02$ \\
\hline Putai 3 & 60.9 & 26.3 & $10.05 \pm 1.71$ & $4.84 \pm 2.37$ \\
\hline Yichu 1 & 63.3 & 49.7 & $9.50 \pm 3.70$ & $9.32 \pm 7.18$ \\
\hline Yichu 2 & 75.8 & 39.4 & $4.25 \pm 1.29$ & $2.25 \pm 0.78$ \\
\hline Yichu 3 & 68.2 & 48.5 & $7.28 \pm 3.20$ & $5.25 \pm 0.62$ \\
\hline Hsuehchia 1 & 86.0 & 50.4 & $9.69 \pm 0.60$ & $5.56 \pm 1.83$ \\
\hline Hsuehchia 2 & 56.5 & 38.2 & $13.32 \pm 2.06$ & $9.33 \pm 1.93$ \\
\hline Hsuehchia 3 & 63.9 & 66.5 & $8.55 \pm 3.19$ & $10.08 \pm 6.39$ \\
\hline Peimen 1 & 71.7 & 40.3 & $12.44 \pm 6.15$ & $6.75 \pm 4.23$ \\
\hline Peimen 2 & 75.5 & 37.0 & $9.26 \pm 1.27$ & $4.55 \pm 0.91$ \\
\hline Peimen 3 & 55.8 & 49.7 & $7.68 \pm 0.60$ & $7.47 \pm 2.23$ \\
\hline Average & $67.5 \pm 8.8$ & $44.1 \pm 10.2$ & $11.55 \pm 4.42$ & $6.80 \pm 2.64$ \\
\hline
\end{tabular}

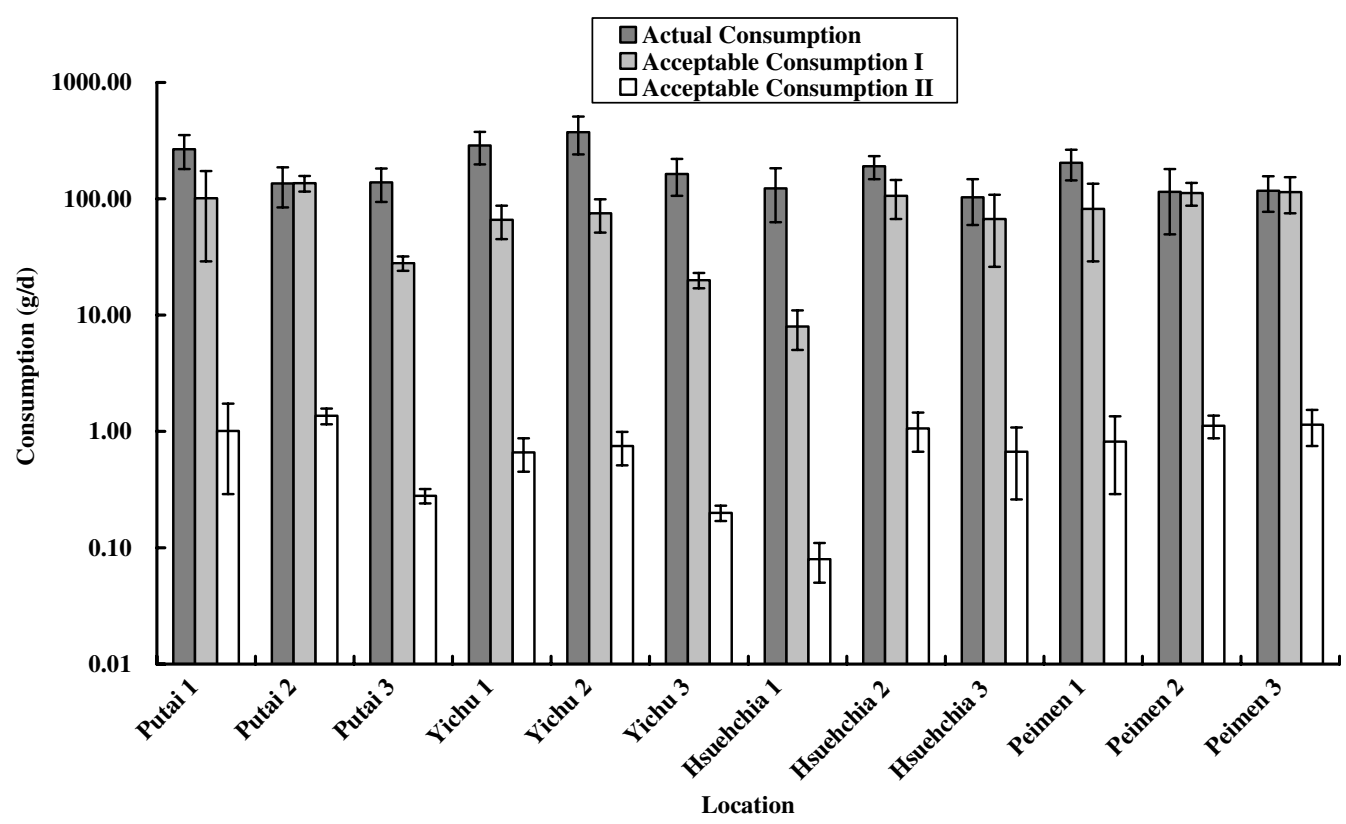

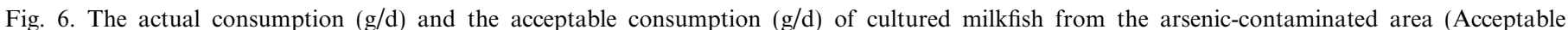
consumption I: TR $=1 \times 10^{-4}$; Acceptable consumption II: TR $=1 \times 10^{-6}$ ).

and 2). The risk-based concentrations $\left(\mathrm{RBC}_{\mathrm{w}}\right)$ for inorganic arsenic concentration in pond water, ranging from $0.06 \pm 0.04 \mu \mathrm{g} / \mathrm{L}$ to $0.45 \pm 0.13 \mu \mathrm{g} / \mathrm{L}$, were lower than the pond water in situ, ranging from $13.34 \pm 7.17 \mu \mathrm{g} / \mathrm{L}$ to $296.96 \pm 32.73 \mu \mathrm{g} / \mathrm{L}$ (Tables 1 and 2). When it was calculated based on the standard $1 \times 10^{-4}$, only one pond (Putai 3) was higher than the risk-based concentration for inorganic arsenic level in milkfish.

\section{Discussion}

Most of the arsenic in the water of culture ponds from the arsenic-contaminated area in southwestern Taiwan is inorganic. Huang et al. (2003) reported a similar phenomenon for the water from the cultured ponds of tilapia (Ore- ochromis mossambicus) in the same arsenic-contaminated area. Edmonds and Francesconi (1993), Macintosh et al. (1996) and Han et al. (1998) have evaluated potential human health risks associated with inorganic arsenic uptake from various kinds of seafood. In their studies, inorganic arsenic in seafood was assumed to be $10 \%$ of total arsenic. Huang et al. (2003) conducted a study measuring the arsenic species in cultured tilapia, demonstrating that the amount of inorganic arsenic is $7.4 \%$ of the total arsenic in this fish. The inorganic arsenic level $(44.1 \pm 10.2 \%)$ we found in milkfish is much higher than the levels in the seafood and tilapia mentioned above. It demonstrates that milkfish might have a lower ability to covert the inorganic arsenic into organic forms, whereas, arsenic in ambient water is often in inorganic form. 
Table 2

Target cancer risk (TR), target hazard quotient (THQ), risk-based inorganic arsenic concentration in fish ( $\mathrm{RBC}$, $\mathrm{mg} / \mathrm{kg}$ ) and risk-based inorganic arsenic concentration in water $\left(\mathrm{RBC}_{\mathrm{w}}, \mu \mathrm{g} / \mathrm{L}\right)$ for consuming cultured milkfish from the arsenic-contaminated area (mean \pm standard error)

\begin{tabular}{|c|c|c|c|c|}
\hline Location & TR & THQ & $\mathrm{RBC}_{\mathrm{f}}$ & $\mathrm{RBC}_{\mathrm{w}}$ \\
\hline Putai 1 & $3.00 \times 10^{-4} \pm 1.53 \times 10^{-4^{* *}}$ & $1.55 \pm 0.79^{* * *}$ & $\begin{array}{l}4.43 \times 10^{-4} \pm 1.81 \times 10^{-4 a} \\
4.43 \times 10^{-2} \pm 1.81 \times 10^{-2 b}\end{array}$ & $\begin{array}{l}0.06 \pm 0.04^{\mathrm{a}} \\
5.64 \pm 3.96^{\mathrm{b}}\end{array}$ \\
\hline Putai 2 & $4.77 \times 10^{-5} \pm 6.92 \times 10^{-6^{*}}$ & $0.25 \pm 0.04$ & $\begin{array}{l}1.78 \times 10^{-3} \pm 8.48 \times 10^{-4 a} \\
1.78 \times 10^{-1} \pm 8.48 \times 10^{-2 b}\end{array}$ & $\begin{aligned} 0.33 & \pm 0.12^{\mathrm{a}} \\
33.32 & \pm 11.94^{\mathrm{b}}\end{aligned}$ \\
\hline Putai 3 & $3.58 \times 10^{-4} \pm 5.43 \times 10^{-5^{* *}}$ & $1.86 \pm 0.28^{* * *}$ & $\begin{array}{r}1.14 \times 10^{-2} \pm 7.09 \times 10^{-4 a} \\
1.14 \pm 7.09 \times 10^{-2 b}\end{array}$ & $\begin{aligned} 0.27 & \pm 0.11^{\mathrm{a}} \\
27.12 & \pm 11.27^{\mathrm{b}}\end{aligned}$ \\
\hline Yichu 1 & $2.09 \times 10^{-4} \pm 5.78 \times 10^{-5^{* *}}$ & $1.09 \pm 0.30^{* * *}$ & $\begin{array}{l}8.70 \times 10^{-4} \pm 4.59 \times 10^{-4 a} \\
8.70 \times 10^{-2} \pm 4.59 \times 10^{-2 b}\end{array}$ & $\begin{aligned} 0.13 & \pm 0.07^{\mathrm{a}} \\
13.00 & \pm 7.34^{\mathrm{b}}\end{aligned}$ \\
\hline Yichu 2 & $2.10 \times 10^{-4} \pm 6.50 \times 10^{-5^{* *}}$ & $1.09 \pm 0.34^{* * *}$ & $\begin{array}{l}7.66 \times 10^{-4} \pm 6.64 \times 10^{-4 a} \\
7.66 \times 10^{-2} \pm 6.64 \times 10^{-2 b}\end{array}$ & $\begin{aligned} 0.37 & \pm 0.12^{\mathrm{a}} \\
36.82 & \pm 12.07^{\mathrm{b}}\end{aligned}$ \\
\hline Yichu 3 & $5.36 \times 10^{-4} \pm 8.52 \times 10^{-5^{* *}}$ & $2.78 \pm 0.44^{* * *}$ & $\begin{array}{l}1.10 \times 10^{-3} \pm 2.30 \times 10^{-4 a} \\
1.10 \times 10^{-1} \pm 2.30 \times 10^{-2 b}\end{array}$ & $\begin{array}{r}0.21 \pm 0.03^{\mathrm{a}} \\
21.22 \pm 2.52^{\mathrm{b}}\end{array}$ \\
\hline Hsuehchia 1 & $7.26 \times 10^{-4} \pm 3.19 \times 10^{-4^{* *}}$ & $3.76 \pm 1.65^{* * *}$ & $\begin{array}{l}2.32 \times 10^{-3} \pm 9.63 \times 10^{-4 a} \\
2.32 \times 10^{-1} \pm 9.63 \times 10^{-2 b}\end{array}$ & $\begin{aligned} 0.45 & \pm 0.13^{\mathrm{a}} \\
44.57 & \pm 12.54^{\mathrm{b}}\end{aligned}$ \\
\hline Hsuehchia 2 & $6.62 \times 10^{-5} \pm 2.86 \times 10^{-5^{*}}$ & $0.34 \pm 0.15$ & $\begin{array}{l}1.80 \times 10^{-3} \pm 9.06 \times 10^{-4 a} \\
1.80 \times 10^{-1} \pm 9.06 \times 10^{-2 b}\end{array}$ & $\begin{aligned} 0.20 & \pm 0.04^{\mathrm{a}} \\
19.83 & \pm 3.67^{\mathrm{b}}\end{aligned}$ \\
\hline Hsuehchia 3 & $2.55 \times 10^{-4} \pm 1.31 \times 10^{-4^{* *}}$ & $1.32 \pm 0.68^{* * *}$ & $\begin{array}{l}8.30 \times 10^{-4} \pm 3.83 \times 10^{-4 a} \\
8.30 \times 10^{-2} \pm 3.83 \times 10^{-2 b}\end{array}$ & $\begin{aligned} 0.11 & \pm 0.08^{\mathrm{a}} \\
11.27 & \pm 7.73^{\mathrm{b}}\end{aligned}$ \\
\hline Peimen 1 & $1.19 \times 10^{-4} \pm 8.14 \times 10^{-5^{* *}}$ & $0.62 \pm 0.42$ & $\begin{array}{l}1.58 \times 10^{-3} \pm 5.51 \times 10^{-4 a} \\
1.58 \times 10^{-1} \pm 5.51 \times 10^{-2 b}\end{array}$ & $\begin{aligned} 0.29 & \pm 0.13^{\mathrm{a}} \\
29.05 & \pm 13.45^{\mathrm{b}}\end{aligned}$ \\
\hline Peimen 2 & $6.37 \times 10^{-5} \pm 1.61 \times 10^{-5^{*}}$ & $0.33 \pm 0.08$ & $\begin{array}{l}1.66 \times 10^{-3} \pm 7.19 \times 10^{-4 a} \\
1.66 \times 10^{-1} \pm 7.19 \times 10^{-2 b}\end{array}$ & $\begin{aligned} 0.38 & \pm 0.08^{\mathrm{a}} \\
37.62 & \pm 8.26^{\mathrm{b}}\end{aligned}$ \\
\hline Peimen 3 & $7.09 \times 10^{-5} \pm 2.03 \times 10^{-5^{*}}$ & $0.37 \pm 0.11$ & $\begin{array}{l}1.50 \times 10^{-3} \pm 3.51 \times 10^{-4 a} \\
1.50 \times 10^{-1} \pm 3.51 \times 10^{-2 b}\end{array}$ & $\begin{aligned} 0.22 & \pm 0.08^{\mathrm{a}} \\
21.61 & \pm 7.59^{\mathrm{b}}\end{aligned}$ \\
\hline
\end{tabular}

\footnotetext{
${ }^{*}>1 \times 10^{-6}$, higher than the safe standard for cancer risk $1 \times 10^{-6}$

${ }^{* *}>1 \times 10^{-4}$, higher than the safe standard for cancer risk $1 \times 10^{-4}$.

${ }^{* * *}>1$, higher than the safe standard for non-cancer risk 1 .

a Calculated based on TR $=1 \times 10^{-6}$.

b Calculated based on TR $=1 \times 10^{-4}$.
}

The inorganic arsenic level in milkfish increases with the inorganic arsenic concentration in pond water. The values of TR and THQ show that consumption of arsenicpolluted milkfish might cause an overexposure of inorganic arsenic and pose cancer and non-cancer risks to human health. The $\mathrm{RBC}_{\mathrm{f}}$ and $\mathrm{RBC}_{\mathrm{w}}$ values indicate that the arsenic levels in groundwater-cultured milkfish and pond water are relatively high. It is recommended that legislation should be established limiting the arsenic levels in pond water and cultured fish.

In a 15-year study of a cohort of 789 patients, an increased mortality from cancers of the liver, lung, bladder and kidney was seen among the patients from the arseniccontaminated area, compared with the general population in the endemic area or compared with the general population of Taiwan (Chen et al., 1980). Several follow-up studies of the Taiwanese population exposed to inorganic arsenic showed an increase in fatal internal organ cancers as well as an increase in skin cancer (Chen et al., 1995,1999,2004). In these studies, the age-adjusted and sex-adjusted mortality for cancers of skin, lung, liver, kidney, bladder and prostate among the residents in the arsenic-contaminated area were found significantly higher than that of the general population of Taiwan. These cancers as well as BFD were documented associating with high levels of arsenic in drinking water. Although a large number of studies have been conducted on dose-response rela- tionship between the arsenic level in drinking water and mortality because of cancers (Wu et al., 1989; Yu et al., 2003), most of these studies involve the connections between arsenic in water and human health, and not so much an appraisal from a food safety perspective.

Some recently published reports on farmed fish have involved analyses of total arsenic accumulation in cultured fish (e.g. Liao et al., 2003; Lin et al., 2005; Jang et al., 2006; Ling and Liao, 2007), but few of them have examined the risk based on the exposure of inorganic arsenic. Liao and Ling (2003) carried out a risk analysis to quantify the inorganic arsenic bioaccumulation in cultured tilapia and large-scale mullet (Liza macrolepis) from the arsenic-contaminated area in Taiwan, as well as the risk caused by consumption of these fish. Lin et al. (2005) demonstrated that the arsenic exposure because of milkfish consumption would pose health risks to residents via the food chain. Chou et al. (2006) have presented a toxicokinetic/toxicodynamic analysis to appraise the risks. In these three studies however, the risk was calculated based on the assumption that inorganic arsenic constitutes $10 \%$ of total arsenic in fish. Our study calculated the risk directly from the measured data and showed that the inorganic arsenic level is $44.1 \pm 10.2 \%$ of total arsenic in milkfish. It demonstrates that the values of TR and THQ for milkfish consumption were underestimated and the $\mathrm{RBC}_{\mathrm{f}}$ and $\mathrm{RBC}_{\mathrm{w}}$ values were overestimated in Lin et al. (2005). 
The inhabitants in the arsenic-contaminated area, who consume the arsenic-contaminated milkfish, might be exposed chronically to arsenic pollution with carcinogenic and non-carcinogenic risks. Public health experts are concerned since it has been known for years that using groundwater for aquaculture is a common situation in the arsenic-contaminated area in Taiwan (Chou et al., 2006). Many cultured stocks, such as eel, carp and shrimp, from this area may also be contaminated by arsenic, but only few quantitative risk estimates have been done. A greater understanding of the arsenic accumulation in human bodies by consuming the arsenic-contaminated seafood and the subsequent health effects is needed. The doseresponse relationships are also necessary to be analyzed in further studies.

\section{Acknowledgment}

We thank Dr. G.P. Chang-Chien and Mr. C.H. Hung for deploying experimental equipment and providing technical assistance and Dr. Y.M. Yeh for her help with statistical analysis. The earlier draft of this manuscript benefited from the comments of Mr. R. Regout. This study was supported by the National Science Council of Republic of China under Grant NSC 94-2313-B-343-001.

\section{References}

Abernathy, C.O., Thomasy, D.J., Calderon, R.L., 2003. Health effects and risk assessment of arsenic. J. Nutr. 133, 1536S-1538S

Borum, D.R., Abernathy, C.O., 1994. Human oral exposure to inorganic arsenic. In: Chappell, W.R., Abernathy, C.O., Cothern, C.R. (Eds.), Arsenic: exposure and health. Science and Technology Letters, Northwood, England, pp. 21-29.

Buchet, J.P., Lison, D., Ruggeri, M., Foa, V., Elia, G., 1996. Assessment of exposure to inorganic arsenic, a human carcinogen, due to the consumption of seafood. Arch. Toxicol. 70, 773-778.

Chen, C.J., Wu, M.M., Lee, S.S., Wang, J.D., Cheng, S.H., Wu, H.Y., 1980. Atherogenicity and carcinogenicity of high-arsenic artesian well water: multiple risk factors and related malignant neoplasms of Blackfoot disease. Arteriosclerosis 8, 452-460.

Chen, C.J., Hsueh, Y.M., Lai, M.S., Shyu, P., Chen, S.Y., Wu, M., Kuo, T.L., Tai, T.Y., 1995. Increased prevalence of hypertension and longterm arsenic exposure. Hypertension 25, 53-60.

Chen, C.J., Hsu, L.I., Tesng, C.H., Hsueh, Y.M., Chiou, H.Y., 1999. Emerging epidemics of arseniasis in Asia. In: Chappell, W.R., Abernathy, C.O., Calderon, R.L. (Eds.), Arsenic exposure and health effects. Elsevier, BV, pp. 113-121.

Chen, C.L., Hsu, L.I., Chiou, H.Y., Hsueh, Y.M., Chen, S.Y., Wu, M.M., 2004. Ingested arsenic, cigarette smoking, and lung cancer risk: a follow-up study in arseniasis-endemic areas in Taiwan. Jama 292, 2984-2990

Chiou, H.Y., Hsueh, Y.M., Liaw, K.F., Horng, S.F., Chiang, M.H., Pu, Y.S., Lin, J.S.N., Huang, C.H., Chen, C.J., 1995. Incidence of internal cancers and ingested inorganic As: a seven-year follow-up study in Taiwan. Cancer Res. 55, 1296-1300.

Chou, B.Y.H., Liao, C.M., Lin, M.C., Cheng, H.H., 2006. Toxicokinetics/ toxicodynamics of arsenic for farmed juvenile milkfish Chanos chanos and human consumption risk in BFD-endemic area of Taiwan. Environ. Int. 32, 545-553.

Donohue, J.M., Abernathy, C.O., 1999. Exposure to inorganic arsenic from fish and shellfish. In: Chappell, W.R., Abernathy, C.O.,
Calderon, R.L. (Eds.), Arsenic exposure and health effects. Elsevier, BV, pp. 89-98.

Edmonds, J.S., Francesconi, K.A., 1993. Arsenic in seafoods: human health aspects and regulations. Mar. Pollut. Bull 25, 665-674.

Falco, G., Llobet, J.M., Bocio, A., Domingo, J.L., 2006. Daily intake of arsenic, cadmium, mercury, and lead by consumption of edible marine species. J. Agric. Food Chem. 54, 6106-6112.

Han, B.C., Jeng, W.L., Chen, R.Y., Fang, G.T., Hung, T.C., Tseng, R.J., 1998. Estimation of target hazard quotients and potential health risks for metals by consumption of seafood in Taiwan. Arch. Environ. Contam. Toxicol. 35, 711-720.

Huang, Y.K., Lin, K.H., Chen, H.W., Chang, C.C., Liu, C.W., Yang, M.H., Hsueh, Y.M., 2003. Arsenic species contents at aquaculture farm and in farmed mouthbreeder (Oreochromis mossambicus) in blackfoot disease hyperendemic areas. Food Chem. Toxicol. 41, 14911500 .

IPCS, 2001. Environmental health criteria on arsenic and arsenic compounds. In: Environmental Health Criteria Series, No. 224: Arsenic and arsenic compounds, second, WHO, Geneva, 521.

Jang, C.S., Liu, C.W., Lin, K.H., Huang, F.M., Wang, S.W., 2006. Spatial analysis of potential carcinogenic risks associated with ingesting arsenic in aquacultural tilapia (Oreochromis mossambicus) in blackfoot disease hyperendemic areas. Environ. Sci. Technol. 40, 1707-1713.

Liao, C.M., Ling, M.P., 2003. Assessment of human health risks for arsenic bioaccumulation in tilapia (Oreochromis mossambicus) and large-scale mullet (Liza macrolepis) from blackfoot disease area in Taiwan. Arch. Environ. Contam. Toxicol. 45, 264-272.

Liao, C.M., Chen, B.C., Singh, S., Lin, M.C., Liu, C.W., Han, B.C., 2003. Acute toxicity and bioaccumulation of arsenic in tilapia (Oreochromis mossambicus) from a blackfoot disease area in Taiwan. Environ. Toxicol. 18, 252-259.

Lin, M.C., Liao, C.M., Liu, C.W., Singh, S., 2001. Bioaccumulation of arsenic in aquacultural large-scale mullet Liza macrolepis from the blackfoot disease area in Taiwan. Bull. Environ. Contam. Toxicol. 67, 91-97.

Lin, M.C., Cheng, H.H., Lin, H.Y., Chen, Y.C., Chen, Y.P., Liao, C.M., Chang-Chien, G.P., Dai, C.F., Han, B.C., Liu, C.W., 2004. Arsenic accumulation and acute toxicity in milkfish (Chanos chanos) from blackfoot disease area in Taiwan. Bull. Environ. Contam. Toxicol. 72, 248-254.

Lin, M.C., Lin, H.Y., Cheng, H.H., Chen, Y.C., Liao, C.M., Shao, K.T., 2005. Risk assessment of arsenic exposure from consumption of cultured milkfish, Chanos chanos (Forsskål), from the arsenic-contaminated area in southwestern Taiwan. Bull. Environ. Contam. Toxicol. $75,637-644$

Ling, M.P., Liao, C.M., 2007. Risk characterization and exposure assessment in arseniasis-endemic areas of Taiwan. Environ. Int. 33, 98-107.

Ling, M.P., Liao, C.M., Tsai, J.W., Chen, B.C., 2005. A PBPK/PD modeling-based approach can assess arsenic bioaccumulation in farmed tilapia (Oreochromis mossambicus) and human health risks. Integr. Environ. Assess. Manag. 1, 40-54.

Liu, C.W., Jang, C.S., Liao, C.M., 2004. Evaluation of arsenic contamination potential using indicator kriging in the Yun-Lin aquifer (Taiwan). Sci. Total Environ. 321, 173-188.

Macintosh, D.L., Spenglet, J.D., Ozkaynak, H., Tsai, L.H., Ryan, P.B., 1996. Dietary exposure to selected metals and pesticides. Environ. Health Perspect. 104, 202-209.

Mandal, B.K., Suzuki, K.T., 2002. Arsenic round the world: a review. Talanta 58, 201-235.

Munoz, O., Devesa, V., Suner, M.A., Velez, D., Montoro, R., Urieta, I., Macho, M.L., Jalon, M., 2000. Total and inorganic arsenic in fresh and processed fish products. J. Agri. Food Chem. 48, 43694376.

Ng, J.C., Wang, J.P., Shraim, A., 2003. A global health problem caused by arsenic from natural sources. Chemosphere 52, 1353-1359.

Phillips, D.J.H., 1990. Arsenic in aquatic organisms: a review, emphasizing chemical speciation. Aquat. Toxicol. 16, 151-186. 
Smedley, P.L., Kinniburgh, D.G., 2002. A review of the source, behaviour and distribution of arsenic in natural waters. Appl. Geochem. 17, 517-568.

Tsai, S.Y., Chou, H.Y., The, H.W., Chen, C.M., Chen, C.J., 2003. The effects of chronic arsenic exposure from drinking water on the neurobehavioral development in adolescence. Neurotoxicology 24, $747-753$.

USEPA, 2006. USEPA region III risk-based concentration table: technical background information. Available from: http://www.epa.gov/ reg3hwmd/risk/human/rbc/rbc1006.pdf.
Wu, M.M., Kuo, T.L., Hwang, Y.H., Chen, C.J., 1989. Dose-response relation between arsenic concentration in well water and mortality from cancers and vascular diseases. Am. J. Epidemiol. 130, 11231132.

Yu, W.H., Harvey, C.M., Harvey, C.F., 2003. Arsenic in groundwater in Bangladesh: a geostatistical and epidemiological framework for evaluating health effects and potential remedies. Water Resour. Res. $39,1146$. 